\title{
Ketidakstabilan Aliran Sekunder pada Saluran Lengkung Berpenampang Persegi
}

\author{
Nursubyakto \\ Jurusan Teknik Mesin, Fakultas Teknik, Universitas Merdeka Malang, Malang \\ Email: nursubyakto@yahoo.com
}

\begin{abstract}
ABSTRAK
Aliran sekunder (secondary flow) adalah aliran yang berpusar. Aliran ini terjadi pada aliran fluida yang melewati saluran yang melengkung atau berbelok, lebih singkat disebut dengan saluran lengkung, dan profil aliran adalah kembar dan saling berlawanan arah. Terjadinya aliran sekunder ini diakibatkan oleh ketidakseimbangan antara tekanan dan gaya sentrifugal di dinding luar saluran. Aliran sekunder menimbulkan turbulensi meski dalam aliran laminer. Dengan meningkatnya kecepatan aliran melewati saluran lengkung akan muncul aliran sekunder baru (aliran sekunder tambahan) dengan intensitas lebih rendah dari aliran sekunder utama dan proses demikian disebut dengan ketidakstabilan aliran sekunder. Aliran sekunder tambahan ini lebih lemah dari aliran sekunder utama. Ketidakstabilan aliran sekunder dapat terjadi dan menghilang tergantung pada lemah kuatnya aliran sekunder tambahan. Saluran lengkung dengan penampang persegi dengan variasi rasio kelengkungan merupakan tinjauan dalam penelitian ini. Rasio kelengkungan 1 sampai 10 dipelajari. Hasil numerik menunjukkan bahwa ketidakstabilan aliran sekunder sangat bergantung pada rasio kelengkungan di mana semakin besar rasio kelengkungan aliran sekunder tambahan cenderung mudah muncul. Pengaruh adanya Aliran Sekunder tambahan terhadap faktor gesekan juga ditunjukkan.
\end{abstract}

Kata kunci: Aliran sekunder, saluran lengkung, penampang persegi.

\begin{abstract}
Secondary flow is the counter rotating vortex that appears in the channel when a fluid flows in a curved channel. The occurence of this secondary flow is caused by imbalance between centrifugal force and pressure on the outer wall of the channel. When Dean number is increased the additional secondary flow appears to the main secondary flow and/or disappears. This paper investigated the occurence of the additional secondary flow to the main flow with rectangular cross section and the radius of curvature varied from 1 to 10. The result shows that increament of curvature ratio the additional Dean voritces appears and beyond of ratio of 4 is constant. The effect of the additional secondary flow to the friction factor is also predicted.
\end{abstract}

Keywords: Secondary flow, curved channel, rectangular cross section.

\section{PENDAHULUAN}

Pipa lengkung atau pipa berbelok digunakan secara luas dalam peralatan industri seperti penukar kalor spiral, mesin-mesin pendingin, reaktor-reaktor pembangkit panas dan banyak ditemui pula pada mesin-mesin panas. Aliran pada saluran lengkung dikarakteristikkan dengan bilangan Dean dengan ditunjukkan oleh pusaran kembar yang berputar berlawanan arah yang tegak lurus pada aliran utama. Pusaran kembar yang berputar berlawanan arah ini umumnya disebut dengan aliran sekunder (secondary flow). Timbulnya aliran sekunder ini disebabkan oleh adanya gaya sentrifugal sewaktu aliran melewati belokan.
Pola aliran yang sama dapat pula disebabkan oleh gaya apung pada arah gravitasi atau medan putaran. Pola tersebut dibangkitkan karena adanya gaya apung atau gaya Coriolis. Pengaruh gaya apung pada saluran ditimbulkan karena adanya perbedaan densitas fluida dengan adanya perbedaan temperatur antar partikel fluida yang melewati saluran sedang pengaruh gaya Coriolis lebih disebabkan karena saluran bergerak melalui fluida. Paper ini lebih menitikberatkan pengaruh gaya sentrifugal dari pada pengaruh gaya apung gaya Coriolis dengan alasan tanpa adanya perlakuan temperatur dan saluran dalam kondisi diam tetapi fluida yang mengalir melewati saluran. 


\section{METODE PENELITIAN}

Aliran sekunder pertama kali dianalisa oleh Dean [1] yang menggunakan teori pertubasi dalam studi teoritisnya pada gerakan fluida yang melewati pipa lengkung. Dean mengemukakan karakteristik pusaran kembar dan simetri dari aliran sekunder. Dean menunjukkan bahwa keserupaan dinamika aliran yang mana aliran sekunder muncul sebagai aliran turbulen di dalam aliran yang laminer. Munculnya aliran sekunder adalah akibat dari ketidakseimbangan antara gaya sentrifugal dan tekanan saat fluida mengenai dinding sisi luar. Aliran semacam itu didefinisikan dengan bilangan tanpa dimensi $K=\operatorname{Re}(a / R)^{1 / 2}$, dan sekarang dinamai dengan bilangan Dean, di mana $R e$ adalah bilangan Reynolds, a adalah diameter pipa, dan $R$ adalah jari-jari kelengkungan pipa. Hasil analisanya terjadi pada jari-jari kelengkungan yang kecil. Pengertian secara fisik dari bilangan Dean adalah perbandingan akar dari perkalian gaya inersia dengan gaya sentrifugal terhadap gaya hambat.

Pada awalnya aliran sekunder diamati terjadi pada pipa lengkung namun penelitian-penelitian dengan penampang bukan bulat (pipa) mulai banyak dilakukan. Secara eksperimen Cheng [2] melaporkan bahwa aliran sekunder dipengaruhi oleh penampang lintang bentuk saluran dan menunjukkan adanya aliran sekunder tambahan (additional secondary flow) yang memiliki intensitas yang lebih rendah dari aliran sekunder utama. Cheng [3] menjelaskan peristiwa ini sebagai ketidakstabilan aliran sekunder yang terjadi. Cheng menjelaskan bahwa kemunculan aliran sekunder tambahan terjadi pada bilangan Dean sama dengan 143 untuk saluran persegi seperti halnya yang dikerjakan oleh Ghia [4]. Namun tidak dijelaskan pada paper mereka ketidakstabilan itu terhadap variasi rasio kelengkungan.

Bentuk penampang L juga diamati oleh Asan [5] yang memperlihatkan aliran sekunder berpasangan dan berlawanan arah. Dari pengamatan tersebut terlihat bahwa aliran sekunder tidak simetri karena menyesuaikan bentuk penampang saluran. Juga tidak diperlihatkan adanya aliran sekunder tambahan dengan penampang $\mathrm{L}$ seperti ini.

Fellouah [6] melakukan kaji eksperimental dan numerik dengan rasio aspek 8 dan rasio kelengkungan 10. Fellouah menunjukkan bahwa ketidakstabilan aliran sekunder terjadi sepasang aliran sekunder tambahan atau lebih. Deskripsi ketidakstabilan aliran sekunder ditampilkan pada serangkaian fotografi hasil eksperimen yang sesuai dengan kajian eksperimen dengan fluida Newton.

Bilangan Dean adalah perkalian bilangan Reynolds dengan akar dari perbandingan diameter pipa dan diameter kelengkungan. Semakin besar diameter kelengkungan maka pipa lengkung akan identik dengan pipa lurus dan karakteristiknya dapat diasumsikan mengikuti pipa lurus. Oleh karena itu untuk menimbulkan aliran sekunder yang disebabkan oleh gaya sentrifugal maka perbandingan kelengkungan harus tertentu/terbatas.

Paper ini merupakan penjelasan secara simulasi hasil eksperimen yang telah dilakukan oleh Cheng dan timbulnya ketidakstabilan aliran sekunder tidak saja diakibatkan oleh bentuk penampang namun juga dipengaruhi oleh rasio kelengkungan. Penampang lintang saluran hanya diamati berbentuk persegi (bujur sangkar) serta peristiwa awal timbulnya aliran sekunder tambahan diamati.

Gambar 1 memperlihatkan sketsa aliran melewati saluran lengkung dengan penampang persegi. Persamaan umum yang dijabarkan menggunakan gambar tersebut sebagai referensi. Secara umum persamaan yang diturunkan berikut ini merupakan persamaan Navier-Stoke [7] dengan melakukan beberapa penyesuaian dan koordinat saluran lengkung semacam ini disebut koordinat toroidal.

Persamaan kontinuitas

$\frac{1}{(\mathrm{R}+\mathrm{X})} \frac{\partial}{\partial \mathrm{X}}[(\mathrm{R}+\mathrm{X}) \mathrm{U}]+\frac{\partial \mathrm{V}}{\partial \mathrm{Y}}=0$

Momentum-X:

$\mathrm{U} \frac{\partial \mathrm{U}}{\partial \mathrm{X}}+\mathrm{V} \frac{\partial \mathrm{U}}{\partial \mathrm{Y}}=-\frac{1}{\rho} \frac{\partial \mathrm{P}}{\partial \mathrm{X}}+\mathrm{v}\left[\nabla^{2} \mathrm{U}-\frac{\mathrm{U}}{(\mathrm{R}+\mathrm{X})^{2}}\right]-\frac{\mathrm{W}^{2}}{(\mathrm{R}+\mathrm{X})}$

dimana, suku $\frac{\mathrm{W}^{2}}{(\mathrm{R}+\mathrm{X})}$ menunjukkan gaya sentrifugal

dalam $\operatorname{arah} X$,

Momentum-Y

$\mathrm{U} \frac{\partial \mathrm{V}}{\partial \mathrm{X}}+\mathrm{V} \frac{\partial \mathrm{V}}{\partial \mathrm{Y}}=-\frac{1}{\rho} \frac{\partial \mathrm{P}}{\partial \mathrm{Y}}+\mathrm{u} \nabla^{2} \mathrm{~V}$

Momentum-Z:

$\mathrm{U} \frac{\partial \mathrm{W}}{\partial \mathrm{X}}+\mathrm{V} \frac{\partial \mathrm{W}}{\partial \mathrm{Y}}+\frac{\mathrm{UW}}{(\mathrm{R}+\mathrm{X})}=-\frac{\mathrm{R}}{\rho \cdot(\mathrm{R}+\mathrm{X})} \frac{\partial \mathrm{P}}{\partial \mathrm{Z}}+\mathrm{v}\left[\nabla^{2} \mathrm{~W}-\frac{\mathrm{W}}{(\mathrm{R}+\mathrm{X})^{2}}\right]$

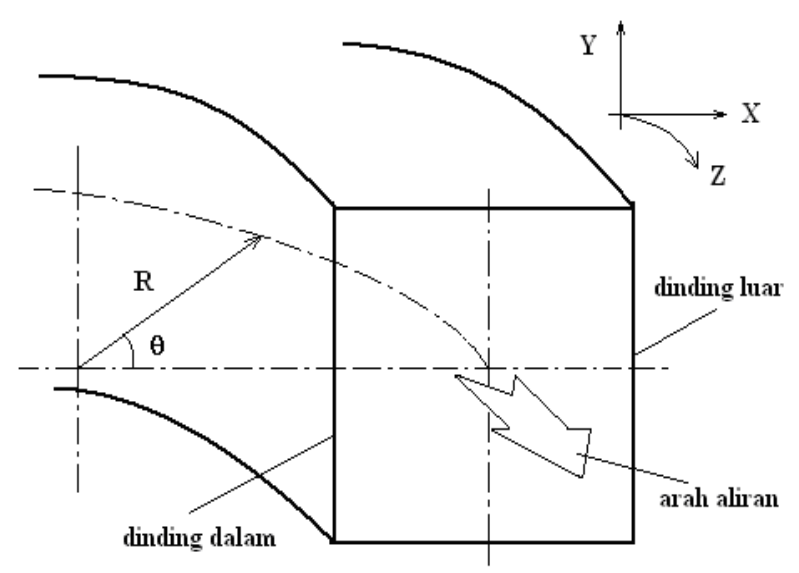

Gambar 1. Sketsa Aliran Melewati Saluran Lengkung 
dimana $\frac{\mathrm{UUW}}{(\mathrm{R}+\mathrm{X})}$ adalah gaya Coriolis dalam arah $Z$, dan $\frac{v U}{(\mathrm{R}+\mathrm{X})^{2}}$ serta $\frac{v \mathrm{~W}}{(\mathrm{R}+\mathrm{X})^{2}}$ adalah gaya-gaya hambat. Perlu dicatat di sini bahwa semua suku-suku gaya hambat diabaikan dalam persamaan momentum karena aliran diasumsikan dalam kondisi berkembang mantap (hydrodynamically fully developed) dan dengan

$$
\nabla^{2}=\frac{1}{(\mathrm{R}+\mathrm{X})}\left[\frac{\partial}{\partial \mathrm{X}}(\mathrm{R}+\mathrm{X}) \frac{\partial}{\partial \mathrm{X}}\right]+\frac{\partial^{2}}{\partial \mathrm{Y}^{2}}
$$

Sebelum menyelesaikan persamaan umum dalam penyelesaian numerik maka persamaan umum dalam bentuk berdimensi perlu diubah ke dalam bentuk persamaan tanpa dimensi dengan menggunakan parameter-parameter seperti yang dilakukan oleh Hwang [8] sebagai berikut. Sebagai catatan, parameter dengan huruf kecil menunjukkan parameter tanpa dimensi.

$$
\begin{array}{ccc}
\mathrm{X}=\mathrm{D}_{\mathrm{e}} \cdot \mathrm{x} & \mathrm{Y}=\mathrm{D}_{\mathrm{e}} \cdot \mathrm{y} & \mathrm{B}=\frac{\mathrm{R}}{\mathrm{D}_{\mathrm{e}}} \quad \mathrm{U}=\mathrm{K}^{2}\left(\frac{\mathrm{u}}{\mathrm{D}_{\mathrm{e}}}\right) \cdot \mathrm{u} \\
\mathrm{V}=\mathrm{K}^{2}\left(\frac{\mathrm{u}}{\mathrm{D}_{\mathrm{e}}}\right) \cdot \mathrm{v} & \mathrm{W}=\overline{\mathrm{W}} \cdot \mathrm{w} & \mathrm{P}=\mathrm{P}_{\mathrm{Z}}(\mathrm{z})+\rho \mathrm{K}^{2}\left(\frac{\mathrm{u}}{\mathrm{D}_{\mathrm{e}}}\right)^{2} \cdot \mathrm{p}
\end{array}
$$

dimana $D_{e}$ adalah diameter hidrolik saluran, $\beta$ adalah rasio kelengkungan saluran, $\overline{\mathrm{W}}$ kecepatan aksial rata-rata, $P_{z}(Z)$ adalah distribusi tekanan fluida dan $K$ adalah bilangan Dean. Persamaan umum tanpa dimensi ditunjukkan seperti berikut,

Persamaan kontinuitas:

$$
\frac{1}{(\beta+x)} \frac{\partial}{\partial x}[(\beta+x) u]+\frac{\partial v}{\partial y}=0
$$

Persamaan momentum-x:

$$
\begin{aligned}
\mathrm{K}^{2}\left[\mathrm{u} \frac{\partial \mathrm{u}}{\partial \mathrm{x}}+\mathrm{v} \frac{\partial \mathrm{u}}{\partial \mathrm{y}}\right]= & -\frac{\partial \mathrm{p}}{\partial \mathrm{x}}+\frac{1}{(\beta+\mathrm{x})} \frac{\partial}{\partial \mathrm{x}}\left[(\beta+\mathrm{x}) \frac{\partial \mathrm{u}}{\partial \mathrm{x}}\right]+ \\
& \frac{\partial^{2} \mathrm{u}}{\partial \mathrm{y}^{2}}-\frac{\mathrm{u}}{(\beta+\mathrm{x})}+\frac{\beta}{(\beta+\mathrm{x})} \mathrm{w}^{2}
\end{aligned}
$$

Persamaan momentum-y:

$\mathrm{K}^{2}\left[\mathrm{u} \frac{\partial \mathrm{v}}{\partial \mathrm{x}}+\mathrm{v} \frac{\partial \mathrm{v}}{\partial \mathrm{y}}\right]=-\frac{\partial \mathrm{p}}{\partial \mathrm{y}}+\frac{1}{(\beta+\mathrm{x})} \frac{\partial}{\partial \mathrm{x}}\left[(\beta+\mathrm{x}) \frac{\partial \mathrm{v}}{\partial \mathrm{x}}\right]+\frac{\partial^{2} \mathrm{v}}{\partial \mathrm{y}^{2}}$

Persamaan momentum-z:

$$
\begin{aligned}
\mathrm{K}^{2}\left[\mathrm{u} \frac{\partial \mathrm{w}}{\partial \mathrm{x}}+\mathrm{v} \frac{\partial \mathrm{w}}{\partial \mathrm{y}}\right]= & \frac{\beta \mathrm{C}}{(\beta+\mathrm{x})}+\frac{1}{(\beta+\mathrm{x})} \frac{\partial}{\partial \mathrm{x}}\left[(\beta+\mathrm{x}) \frac{\partial \mathrm{w}}{\partial \mathrm{x}}\right]+ \\
& \frac{\partial^{2} \mathrm{w}}{\partial \mathrm{y}^{2}}-\frac{\mathrm{w}}{(\beta+\mathrm{x})^{2}}-\mathrm{K}^{2} \frac{\mathrm{uw}}{(\beta+\mathrm{x})}
\end{aligned}
$$

dimana $C$ adalah konstanta yang menunjukkan penurunan tekanan dalam arah aksial $z$ dan didefinisikan dengan, $C=-\frac{D e^{2}\left(\frac{\partial_{z}}{\partial Z}\right)}{\mu \bar{W}}$. Parameter, $K^{2}=\left(\frac{\bar{W} D_{e}}{v}\right)^{2} \cdot\left(\frac{D_{e}}{R}\right)$, memberikan gambaran pengaruh dari gaya sentrifugal pada aliran.

Nilai $C$ untuk aliran ditentukan dengan mengevaluasi kontiunitas global pada suatu penampang lintang saluran seperti diberikan pada persamaan berikut.

$\iint\left(\frac{\beta+x}{\beta}\right) \cdot w \cdot d x \cdot d y=\frac{a \cdot b}{D e^{2}}$

dimana pada sisi sebelah kiri menunjukkan laju fluks volume pada penampang lintang saluran dan sisi sebelah kanan menunjukkan laju aliran fluks total. Fluida mengalir diasumsikan tidak terjadi slip pada dinding-dinding saluran sehingga seluruh kecepatan pada dinding sama dengan nol. Selain itu fluida yang digunakan adalah fluida yang takmampu mampat.

Faktor gesekan (friction factor) saluran lengkung seperti yang dilakukan oleh Hwang [8] adalah sebagai berikut.

$$
f \operatorname{Re}=2 \cdot \frac{\overline{\beta+x}}{\beta} \cdot \frac{\partial w}{\partial n}
$$

Persamaan umum bentuk tanpa dimensi kemudian diformulasikan ke dalam bentuk fungsi arus-vortisitas lalu didiskritasasi dengan menggunakan metode volume atur (control volume). Perubahan persamaan umum ke fungsi arus-vortisitas adalah untuk menyederhanakan persamaan umum dari bentuk 3 dimensi menjadi 2 dimensi tanpa mengurangi ketelitian eksekusi program. Kelebihan dari pendiskritisasian dengan volume atur adalah ketidaktergantungan yang signifikan terhadap jumlah nodal. Setelah persamaan umum diubah ke bentuk diskrit kemudian secara aljabar diskritasi dibentuk dalam bentuk matrik yaitu matrik koefisien dan matrik variabel serta matrik konstanta. Cara pengubahan diskritisasi menjadi bentuk matrik aljabar adalah untuk menerjemahkan diskritasi dalam algoritma numerik sehingga dengan algoritma ini penulisan program dapat dilakukan. Program simulasi numerik diselesaikan dengan menggunakan jumlah nodal $40 \times 40$ dengan menerapkan aturan staggered grid.

Urutan algoritma numerik yang telah ditulis ke dalam bahasa pemorograman adalah sebagai berikut: Matrik koefisien dipecah menjadi dua bagian yaitu menjadi matrik segitiga bawah dan matrik segitiga atas untuk mempercepat proses konvergensi perhitungan. 
Pemecahan matrik dan penyelesaiannya menggunakan cara yang dikembangkan oleh Peric [9] yaitu dengan Simple Implicite Procedure dan rangkaian keseluruhan program mengikuti aturan yang dikembangkan oleh Patankar [10] yaitu metode SIMPLER. Tingkat konvergensi hitungan dihentikan ketika seluruh parameter telah mencapai $10^{-3}$ dengan faktor relaksasi untuk penyelesaian matrik diberi nilai tetap dan faktor relaksasi untuk parameter kecepatan berubah-ubah guna mencapai syarat konvergensi. Bahasa pemrograman yang digunakan adalah Visual Basic dan untuk memvisualisasikan hasil program menggunakan perangkat lunak ploting.

\section{HASIL DAN PEMBAHASAN}

Kriteria konvergensi untuk matrik, kecepatan arah $x$, dan kecepatan arah $y$ telah ditetapkan sebesar 0,9. Begitu juga kriteria konvergensi untuk vortisitas, fungsi arus dan kecepatan aksial masingmasing adalah 0,1 dan 0,8 dan 0,7. Ketiga kriteria konvergensi yang terakhir ini sangat sensitif karena vortisitas, fungsi arus, dan kecepatan aksial merupakan turunan pertama (the first derivative)
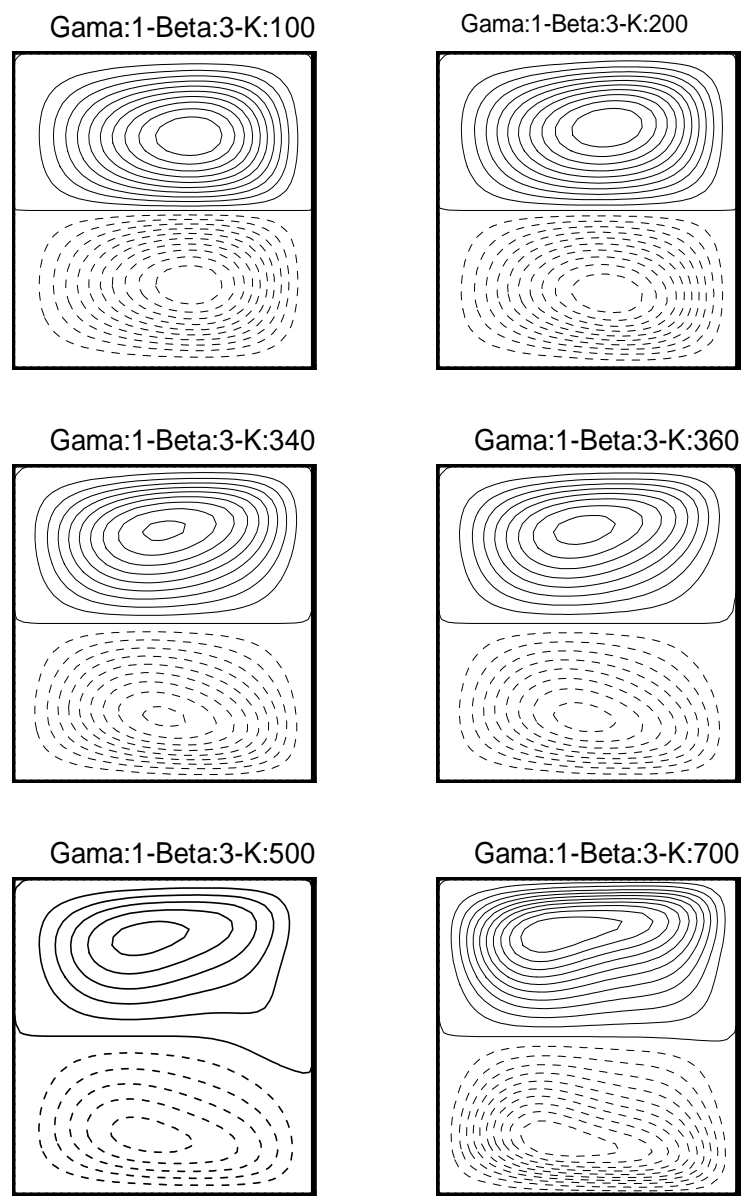

sehingga ketiganya sulit mencapai konvergensi dan nilainya perlu diatur sedemikian rupa agar konvergensi tercapai.

Contoh hasil simulasi program yang digambar sebagai fungsi arus dapat dilihat pada Error! Reference source not found. dengan rasio kelengkungan sama dengan 3 (beta) dan variasi bilangan Dean (K). Sampai dengan bilangan Dean 360 aliran sekunder utama tampak stabil yaitu dengan ditunjukkannya sepasang pusaran kembar yang saling berlawanan arah. Pada bagian atas dalam saluran pusaran berlawan arah dengan jarum jam bernilai positif dan digambar dengan garis kontinu sedang pada sisi bawah pusaran searah dengan arah jarum jam digambar dengan garis putus-putus dan bernilai negatif.

Pada bilangan Dean sama dengan 380 mulai tampak ketidakstabilan aliran sekunder dengan munculnya aliran sekunder tambahan yang terlihat lebih kecil ukurannya dan muncul dari dinding luar saluran. Kemunculan aliran sekunder tambahan mulai akan menghilang pada bilangan Dean 400 . Ketika bilangan Dean mencapai 500 aliran sekunder tambahan lenyap dan kenaikan bilangan lebih lanjut bilangan Dean aliran sekunder tampak lebih
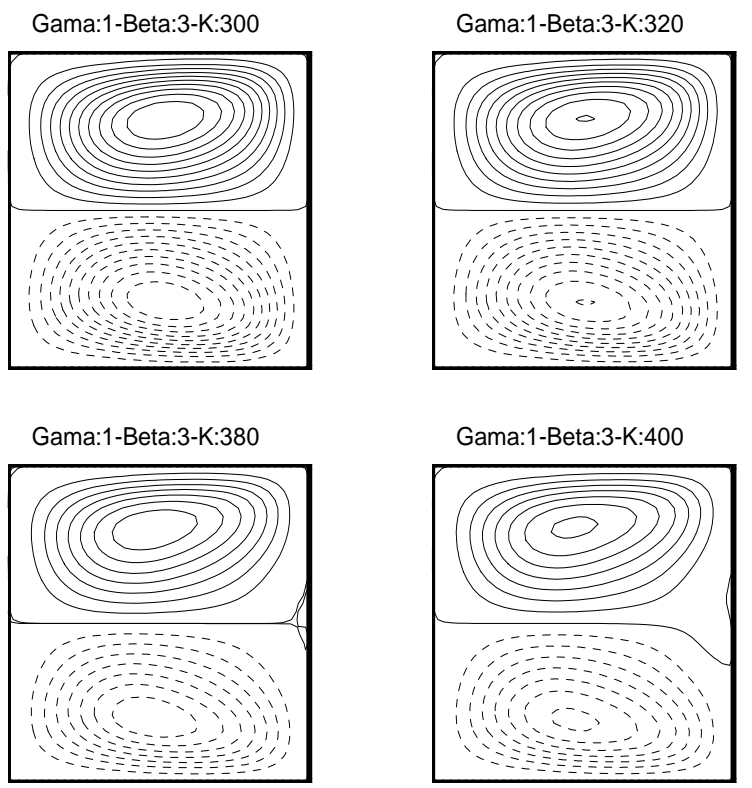

Gama:1-Beta:3-K:400

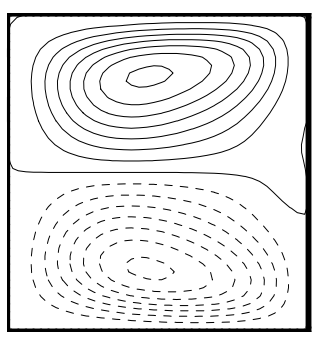

Gama:1-Beta:3-K:800
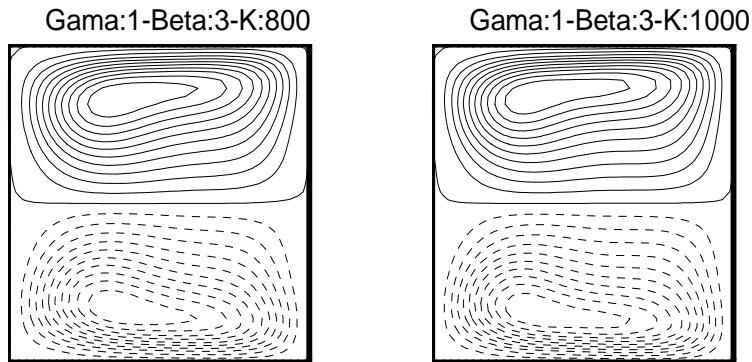

Gambar 2. Rangkaian Simulasi Fungsi Arus Hasil Perhitungan dengan $\gamma=1, \beta=3$ dan Variasi Bilangan Dean 


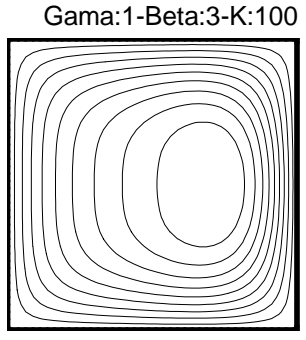

Gama:1-Beta:3-K:340

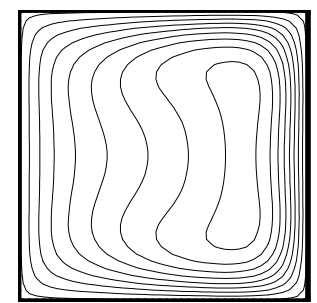

Gama:1-Beta:3-K:500

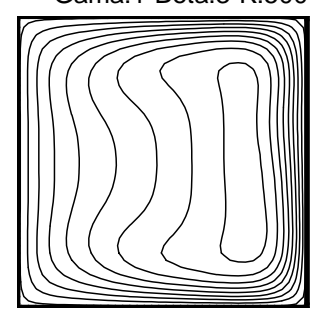

Gama:1-Beta:3-K:200

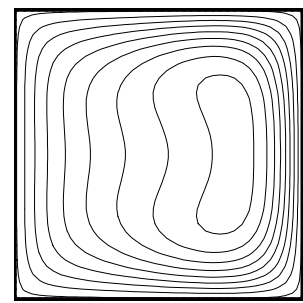

Gama:1-Beta:3-K:360

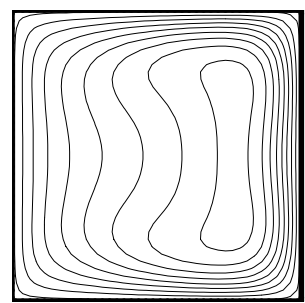

Gama:1-Beta:3-K:700

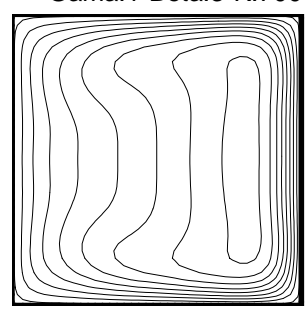

Gama:1-Beta:3-K:300

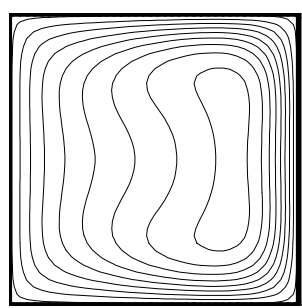

Gama:1-Beta:3-K:380

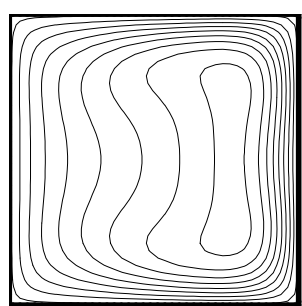

Gama:1-Beta:3-K:800

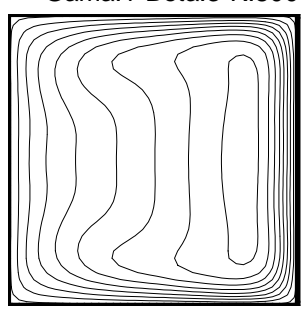

Gama:1-Beta:3-K:320

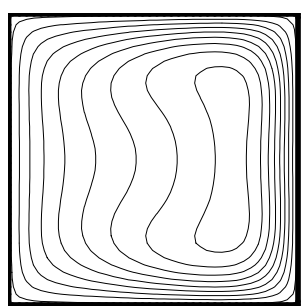

Gama:1-Beta:3-K:400

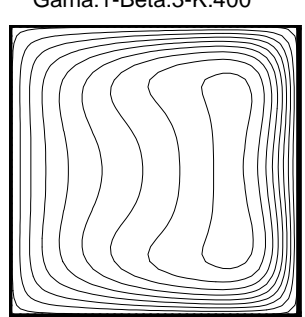

Gama:1-Beta:3-K:1000

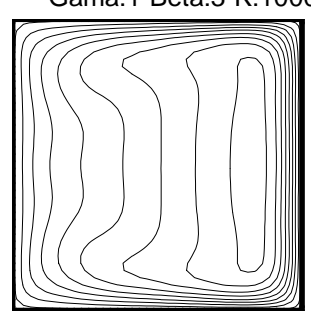

Gambar 3. Rangkaian Simulasi Kecepatan Aksial Melewati Saluran dengan $\gamma=1, \beta=3$ dan Variasi Bilangan Dean

stabil. Munculnya aliran sekunder tambahan ini menunjukkan bahwa aliran sekunder tidak stabil (ketidakstabilan aliran sekunder). Hal ini juga menunjukkan tambahan turbulensi pada aliran.

Error! Reference source not found. memperlihatkan serangkaian simulasi numerik kecepatan aksial dengan peningkatan bilangan Dean yang berhubungan dengan Error! Reference source not found.. Pada dinding luar, dinding luar terletak pada sisi sebelah kanan dari penampang saluran, terlihat bahwa perubahan adanya aliran sekunder tambahan menyebabkan timbulnya tonjolan yang makin besar kemudian menghilang. Proses demikian menunjukkan bahwa ketidakseimbangan antara gaya sentrifugal dan tekanan pada dinding luar terjadi.

Ketidakstabilan aliran sekunder muncul secara sedikit demi sedikit kemudian menghilang dalam aliran. Ketidakstabilan ini telah banyak diamati oleh beberapa peneliti namun pertumbuhan terjadinya ketidakstabilan belum ada laporan yang menjelaskan secara rinci. Pengaruh aliran sekunder tambahan pada faktor gesekan sangat kecil karena aliran sekunder tambahan intensitasnya sangat kecil jika dibandingkan dengan aliran sekunder utama.

Pada Error! Reference source not found. memperlihatkan tampilan fungsi arus sebagai hasil simulasi numerik dengan rasio kelengkungan bervariasi untuk mengamati nilai kritis bilangan Dean di mana terjadinya aliran sekunder tambahan mulai muncul. Nilai bilangan Dean kritis cenderung terus menurun dengan naiknya variasi rasio kelengkungan dan pada nilai rasio kelengkungan lebih dari 4 nilai bilangan Dean kritis relatif konstan. Grafik pada Gambar 5 menunjukkan hubungan antara nilai bilangan Dean kritis terhadap variasi rasio kelengkungan di mana dapat disimpulkan bahwa di bagian bawah kurva merupakan daerah stabil dan daerah di atas kurva merupakan daerah tidak stabil atau area ketidakstabilan yang pertama aliran sekunder bila aliran sekunder tambahan dapat muncul dan menghilang. Hilangnya aliran sekunder tambahan menunjukkan bahwa gaya sentrifugal dengan tekanan pada dinding luar terjadi ketidakseimbangan awal.

Gambar 6 memperlihatkan faktor gesekan terhadap bilangan Dean dengan variasi rasio kelengkungan. $f R e-3$, misalnya, menunjukkan faktor gesekan dengan rasio kelengkungan 3. Secara umum faktor gesekan akan cenderung naik dengan kenaikan bilangan Dean dan rasio kelengkungan. Perlu dicatat di sini bahwa pada rasio kelengkungan lebih besar dari 4 faktor gesekan cenderung relatif memiliki pola yang sama sehingga peningkata rasio kelengkungan lebih lanjut faktor gesekan akan berimpit. 

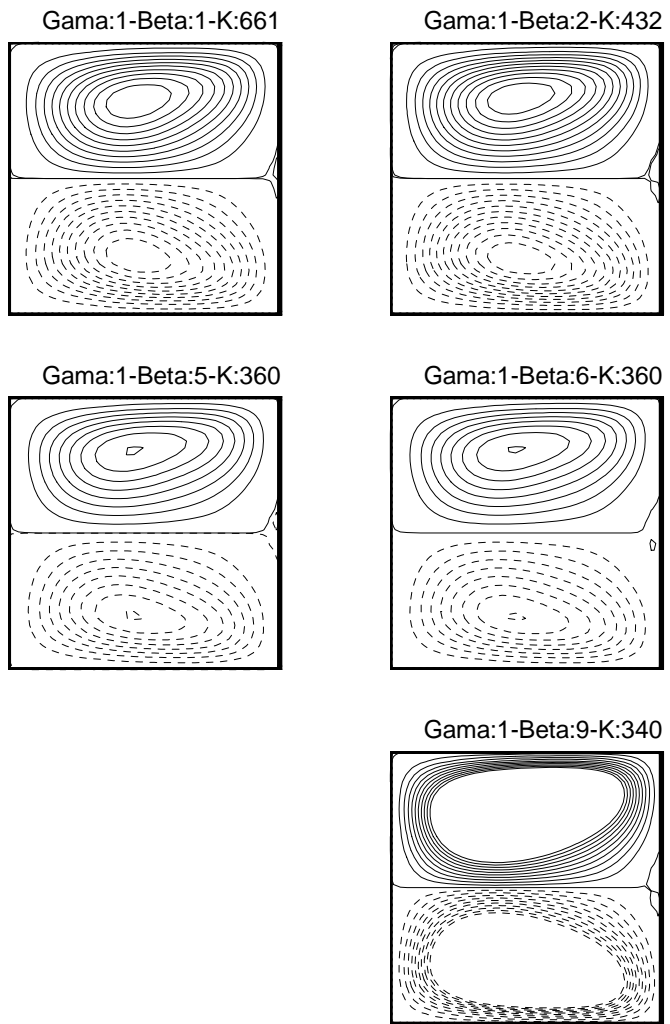

Gama:1-Beta:3-K:380
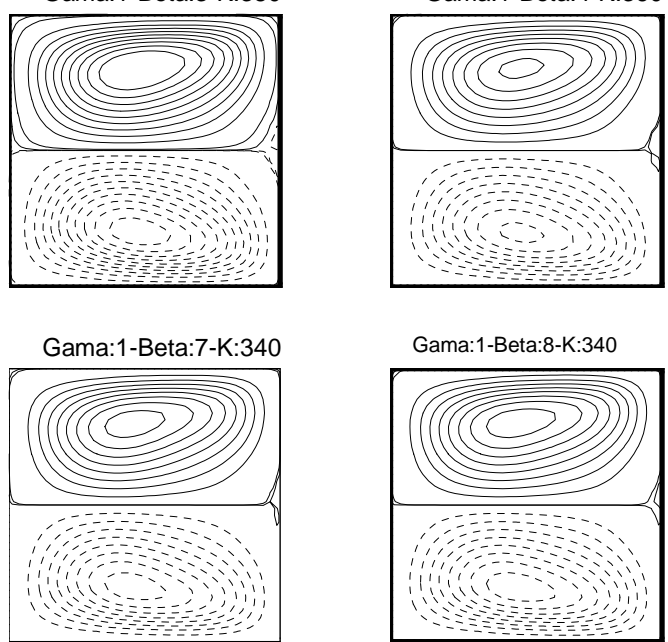

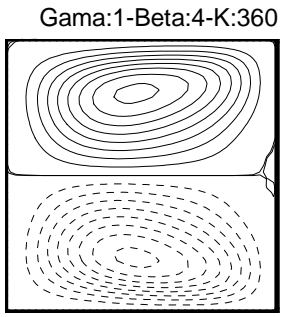

Gama:1-Beta:10-K:340

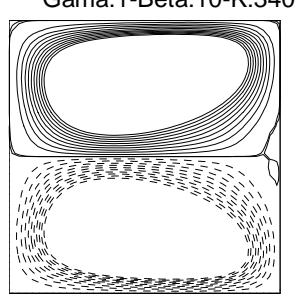

Gambar 4. Rangkaian Awal Terjadinya Ketidakstabilan Aliran Sekunder Melewati Saluran Lengkung dengan Variasi Rasio Kelengkungan

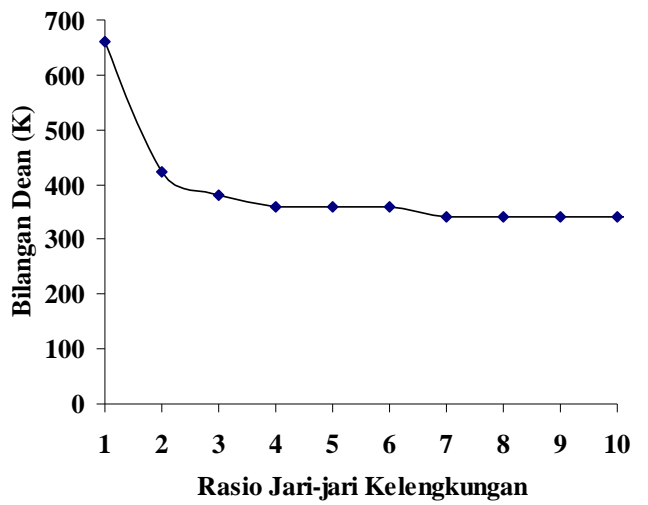

Gambar 5. Nilai Kritis Ketidakstabilan Aliran Sekunder

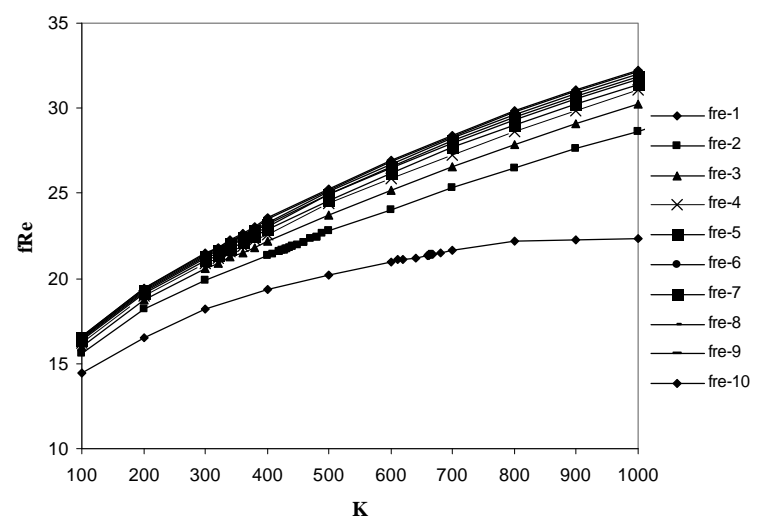

Gambar 6. Faktor Gesekan Terhadap Bilangan Dean

\section{KESIMPULAN}

Ketidakstabilan aliran sekunder (utama) pada saluran lengkung berpenampang persegi ditunjukkan dengan adanya aliran sekunder tambahan di mana kemunculannya dipengaruhi oleh rasio kelengkungan dan bilangan Dean. Aliran sekunder tambahan bisa muncul dan hilang bila bilangan Dean dinaikkan lebih lanjut. Ketidakstabilan aliran sekunder pada nilai bilangan Dean kritis dengan adanya aliran sekunder tambahan kurang berpengaruh pada faktor gesekan karena intensitasnya sangat rendah dibandingkan dengan aliran sekunder utama. Namun rasio kelengkungan sangat mempengaruhi faktor gesekan sampai pada rasio kelengkungan 4 dan bila lebih dari rasio ini kurang signifikan pengaruhnya.

\section{DAFTAR PUSTAKA}

1. W. R. Dean, "The Stream-Line Motion of Fluid in a Curved Pipe", Philosophical Magazine, Vol. 5 no. 30, pp. 673-695, 1928.

2. K. C. Cheng and S. Y. Mok, "Flow Visualisation Studies on Secondary Flow Patterns and Centrifugal Instability Phenomena in Curved Tubes", 1970.

3. K. C. Cheng, L. Ran Chau, and O. Jenn Wuu, "Fully Developed Laminar Flow in Curved Rectangular Channels", Transactions of the 
ASME. Series I, Journal of Fluids Engineering, Vol. 98, pp. 41-48, 1976.

4. K. N. Ghia and J. S. Sokhey, "Laminar Incompressible Viscous Flow in Curved Ducts of Regular Cross-Sections", Transactions of the ASME, Vol. Series I, p. 1977, 1977.

5. H. Asan and H. Kucuk, "A Numerical Computation of Heat and Fluid Flow in L-Shaped Curved Channel", Heat Transfer Engineering, Vol. 28 (2), pp. 112-119, 2007.

6. H. Fellouah, C. Castelain, A. O. E. Moctar, and H. Peerhossaini, "Detection of the Onset of Dean Instability and Effects of the Rheological Behavior in Non-Newtonian Fluids", Journal of Physics: Conference Series 137, 2008.
7. R. B. Bird, W. E. Stewart, and E. N. Lightfoot, "Transport Phenomena", John Wiley \& Sons, 1960.

8. G. J. Hwang and C. H. Chao, "Forced Laminar Convection in a Curved Isothermal Square Duct", Trans. of the ASME, Vol. 113, pp. 48-55, 1991.

9. M. Peric, "Efficient Semi-Implicit Solving Algorithm for Nine-Diagonal Coefficient Matrix", Numerical Heat Transfer, Vol. 11, pp. 251-79, 1987.

10. S. V. Patankar, "Numerical Heat Transfer and Fluid Flow", Washington D.C.: Hemisphere Publishing Corporation, 1980. 